\title{
JOGO DIGITAL COMO FERRAMENTA PEDAGÓGICA
}

\author{
BRASÍLIA/DF MAIO/2018
}

\author{
Rosana Amaro - UnB - rosanaead@unb.br \\ Welinton Baxto - MEC - wbaxto@gmail.com \\ Jitone Leônidas Soares － UnB - jitoneleonidas@gmail.com \\ Tipo: Relato de Experiência Inovadora (EI) \\ Categoria: Métodos e Tecnologias \\ Setor Educacional: EDUCAÇÃO SUPERIOR
}

\begin{abstract}
RESUMO
Este relato de experiência apresenta os jogos digitais como possibilidade da prática pedagógica, desenvolvida na semana universitária na Faculdade de Educação Física da Universidade de Brasília, com estudantes de graduação em Educação Física e Pedagogia, professores da rede pública/privada de ensino básica e pessoas interessadas na temática. A metodologia é descritiva apoiada com aplicação de questionário e análise qualitativa acerca da reação dos participantes na oficina. Utilizou-se na aplicação dos jogos digitais o dispositivo "Kinect Xbox one", TV Digital, Computador e acesso à internet, a fim de debater com especialista, via webconferência, e simular com os participantes a prática pedagógica por meio do jogo, da dança, da luta e do atletismo com dispositivo digital. Do contexto, a proposta se mostrou inovadora induzindo que os jogos digitais poderão ser pensados como possibilidade para a prática pedagógica dos professores da educação básica pela possibilidade da interação com os jogos digitais, em duplas ou pequenos grupos, em ações cooperativas de modo consensual.
\end{abstract}

Palavras-chave: jogos digitais, prática pedagógica, ferramenta pedagógica 


\section{Introdução}

Há tempos que se percebe o avanço da virtualização do corpo com apoio das mídias interativas, especialmente influenciados pelos jogos digitais que, possivelmente, pela sua característica de onipresença pode ter reverberado na cultura corporal do movimento em diferentes espaços. Quando nos referirmos aos jogos, jogos digitais, jogos computadorizados e suas variações, entendemos que possam ser termos com compreensões aproximadas entre eles. Porém, é relevante dar importância à modelação dos jogos digitais enquanto ferramenta pedagógica na prática corporal por interação entre sujeito e tecnologia.

Sabe-se que a interatividade é uma realidade, sobretudo, uma necessidade das gerações atuais e das novas gerações. Apesar das coerentes evidências que apresentam registros relacionados a movimentos de utilização das TICs, relações sociais coletivas e interativas proporcionada por jogos digitais, Costa (2016) revela que os jogos digitais ganham cada dia mais adeptos, entretanto, sustentam um status de objeto desconhecido e muitas vezes temido, por uma parte importante dos educadores.

Observa-se no cotidiano uma grande variedade de jogos digitais, especialmente na categoria do videogame. Essa categoria pode ser vislumbrada em experiências de aprendizagem a partir de intervenções na prática corporal. Nesta lógica, alguns videogames quando tratados com intencionalidade poderão incorporar identidade, interação, customização, desafio, sentidos contextualizados, pensamento sistemático, exploração, revisão dos objetivos, conhecimento distribuído, entre outros. Os jogos digitais nos desafiam a "tornar a aprendizagem", dentro e fora das escolas, muito mais atrativa, reflexiva e estratégica, a fim de que possa favorecer formação dos sujeitos e usuários críticos de tecnologias.

Neste caminho, o presente relato de experiência apresenta os jogos digitais como possibilidade da prática pedagógica, desenvolvida na semana universitária na Faculdade de Educação Física da Universidade de Brasília. O público alvo constituído por estudantes de graduação em Educação Física e Pedagogia, professores da rede pública/privada de ensino básica e pessoas interessadas na temática. A metodologia é descritiva apoiada com aplicação de questionário e roda de conversa com análise qualitativa acerca da reação dos participantes na oficina. No corpo do relato são apresentados os aspectos conceituais, os resultados e análises da oficina "Jogo Digital como possibilidade de Ferramenta Pedagógica", que nos apresentam a interação com os jogos digitais, quando intencional, pode ser uma prática pedagógica inovadora em ambiente educacional. 


\section{Jogo Digital e Eletrônico um breve Contexto Histórico}

Em uma breve contextualização histórica acerca da evolução dos jogos eletrônicos, 1958 demarcou o surgimento do primeiro jogo de entretenimento conhecido por "Tennis for two". Anteriormente, 1947 surgiam a primeira patente de jogo, entretanto, não se tornou público devido ao alto custo. Desse tempo em diante, a evolução dos jogos eletrônicos foi progressivamente se desenvolvendo e criando possibilidades em diversas áreas, passando do entretenimento ao campo educacional e corporativo.

Ampliando a compreensão acerca do Jogo Eletrônico, também em expressão semelhante (jogo digital, game e videogame) Cruz Junior (2013) explica que o jogo eletrônico se caracteriza em dois diferentes aspectos:

combina duas facetas distintas, mas intimamente relacionadas, a saber: a) hardware constituída por todo o tipo de suporte técnico, plataforma ou unidade de armazenamento física, obrigatório(a) ao desenvolvimento da atividade (ex: consoles, arcades e etc.); b) software - são os jogos, em si, ou seja, o conjunto de informações específicas alojadas em cada hardware, que é responsável por criar o universo simbólico pelo qual se envereda o jogador. (CRUZ JUNIOR, 2013, p. 290).

Ainda Cruz Junior (2013) explica que a visível evolução técnica dos games é consequência de aspectos econômicos e culturais. O infográfico publicado no site "The Economist' ilustrou a evolução dos videogames de maior sucesso, sendo a primeira geração Magnavox Odyssey (1972) e ainda, atual, oitava geração, os consoles PS4 e Xbox One, este último envolvendo jogos de movimento.

Todavia, o jogo na visão de Huizinga (2008) é uma atividade livre, "não séria", fora do contexto da vida habitual, capaz de envolver o jogador de forma intensa. Enquanto, os jogos computadorizados, segundo Frasca (2001) tratam-se de quaisquer modalidades de software de entretenimento por computador, que se utiliza de textos e imagens em plataformas eletrônicas, incluindo, computadores pessoais ou consoles operados por um ou vários jogadores em ambientes físicos ou em redes de computadores (Lan / Wan networks).

No olhar de Juul (2010) os jogos digitais podem ter uma interface mimética com alcance de um público ampliado a partir do engajamento dos jogadores em manifestações culturalmente conhecidas e valorizadas. São exemplos, as danças, vivências em experiências de lazer e práticas no boliche, esportes coletivos e individuais, jogos de tênis, apresentações com guitarra, pilotagem de lanchas, aviões, carros entre outros, por 
meio de interfaces que imitam as ações físicas reais, permitindo a quem joga desenvolver, aperfeiçoar e exibir habilidades relacionadas a tais práticas. Infere-se que os jogos digitais criados com características miméticas, tendem a definir forma de interação entre os jogadores e os jogos. Nesta perspectiva, Baracho et al. (2012) registra a empresa japonesa Nintendo, em 2006, lançou no mercado o videogame Wii, em intervenção pioneira neste tipo de aplicação, em contrapartida, Microsoft lançou, em 2010, o Xbox com tecnologia Kinect. Ambos se classificam em console de jogo, no entanto, o modelo Wii, apresentou-se inovador pela possibilidade de combinar movimento reais e interação de joystick. O modelo Xbox também apresenta interação de joystick (movimento por pressão de botões), mas inovou pela possibilidade de interação corporal direta com o sensor Kinect, liberando o jogador das amarras do controle nas mãos, possibilitando ainda a utilização de jogos digitais com base na movimentação corporal.

A bibliografia especializada aponta que essa nova forma de interação por meio dos jogadores que se movimentam e possuem seus movimentos captados, interpretados e apresentados em jogos digitais, tem recebido diferentes denominações, tais como: exergames, exergaming, activity-promoting video games, physically interactive video game, active video gaming, motion-sensing video game, activity promoting computer games, active video games, entre outras, sendo que a expressão exergames (EXG), por ser uma das mais utilizadas na literatura.

Historicamente, Baracho et al. (2012) destaca que os videogames surgiram na década de 1960 e tinham como objetivo inicial o entretenimento (REIS; CAVICHIOLLI, 2008), porém, dados recentes mostram que eles vêm se aprimorando e reorganizando o tempo do usuário que antes era dedicado à música, à televisão e ao cinema (CARELLI, 2003). Os jogos digitais de movimento no cenário da cultura digital atual são muito mais que uma opção de lazer, mas sim, potenciais ferramentas pedagógicas para intervenções em diferentes campos do conhecimento, como área da saúde (reabilitação), aulas de Educação Física.

\section{Jogo Digital como possibilidade de Ferramenta Pedagógica}

Passado algumas décadas da efervescência da sala de informática na escola como possibilidade de empoderamento dos professores e estudantes com utilização de computadores, os professores depararam-se com outras nuances, a aplicação das tecnologias digitais com metodologias e estratégias para melhorar a prática docente e da aprendizagem de seus estudantes. Atualmente, observa-se tendência quanto à utilização dos jogos digitais como ferramenta pedagógica no contexto escolar, 
intervenção de atividades e jogos digitais com o uso do tablet, computadores e xBox kinect e PS4. Porém, há um grande desafio em desvelar de como os jogos digitais poderão favorecer a elevação da qualidade educacional. Não é de se estranhar com essa dificuldade, apontada por Cruz Junior $(2013,289)$, que "[...] é lícito afirmar que os jogos digitais ainda se caracterizam como um conceito marcado pela ausência de consensos definitivos".

Observa-se o número crescente de professores que se esforçam para quebrar 0 paradigma do fazer de suas práticas por intermédio dos jogos digitais. Por exemplo, com tablet, que segundo Nascimento e Liz (2017) consideram uma importante estratégia no ensino da língua portuguesa para crianças surdas. Mas, advertem De Paula e Valente (2016) que os "jogos digitais não devem ser encarados como uma solução mágica para a Educação: é necessário compreender as especificidades dos dois campos, tanto do processo educacional quanto dos videogames para que essa relação seja estabelecida de forma proveitosa".

Enfatiza-se que as tecnologias digitais quando tratadas com finalidade pedagógica podem ser aliadas para o processo ensino e aprendizagem na educação básica e superior, considerando que as tecnologias passaram a fazer parte do cotidiano em ambientes escolares, segundo Francisco e Silva (2015). Os estudos de Carvalho, Barbosa e Silva (2014) com uso de tecnologias com criança com idade de seis anos ainda em fase de alfabetização apontaram que as crianças estão tendo acesso a essa tecnologia cada vez mais cedo, assim, infere-se que poderá reverberar na maneira como os professores e estudantes irão se relacionar no processo educativo. Essa tendência é observada quando da interação da criança com tecnologia em seu ambiente familiar, como os próprios autores denominaram de sociedade "tecnológica". Por outro lado, essa mesma criança, mesmo em processo de alfabetização, demonstrou maior facilidade de manuseio e usabilidade com as tecnologias, possivelmente, pelo fato de ter adquirido acesso prévio naquelas ou em outras tecnologias.

Neste aspecto, as tecnologias e jogos digitais quando empregados de forma intencional em ambientes educacionais, acredita-se que poderão ser aliadas nas práticas pedagógica dos professores para ganhos de aprendizagens de seus educandos, como apresentaram Ramos e Segundo (2018) nos estudos que sobre os efeitos do uso de jogos digitais no contexto escolar para o aprimoramento da atenção e da flexibilidade cognitiva:

Os jogos digitais têm sido associados a ganhos em relação ao aprimoramento de aspectos cognitivos. A partir da interação com esse tipo de jogo, os sujeitos jogadores 
têm um tempo menor de reação, melhoria no desempenho relacionado às habilidades visuais básicas e a atenção ( $\mathrm{Li}$ et al., 2010); exercitam habilidades relacionadas à atenção, como o aumento do número de objetos que são percebidos simultaneamente, a atenção seletiva e a atenção dividida (Feng; Spence; Pratt, 2007; Dye; Bavelier, 2010); melhoram o desempenho cognitivo, aprimorando a capacidade de fazer mais de uma tarefa ao mesmo tempo e de tomar decisões executivas (Boot et al., 2008), (RAMOS E SEGUNDO, 2018, p.531).

entendimento acerca da flexibilidade cognitiva para os autores citando Diamond (2009, p. 18) refere-se à "[...] capacidade do indivíduo de alternar com facilidade e rapidez as perspectivas ou o foco de atenção ajustando de modo flexível a novas exigências ou prioridades e a poder raciocinar de maneira não convencional". Observase que o indivíduo se apresenta com predisposição para a mudança, conforme o momento de estímulo. Nesse estudo foram apontados que os jogos digitais podem contribuir para aperfeiçoamento das habilidades cognitivas, em decorrências as inúmeras repetições que determinado jogo pode proporcionar ao usuário. Pode-se induzir que o jogo digital e as tecnologias quando aplicados na educação formal com intencionalidade poderão se apresentar como possibilidades de ferramentas pedagógicas.

Assim, pode-se chegar ao entendimento de que essas ferramentas tendem favorecer a apreensão, por meio lúdico e flexibilidade cognitiva, de aquisição de conhecimento, bem como, possibilitar a melhoria da prática docente, por ser considerada a oficina jogo digital pelos participantes, um ambiente mais descontraído, todavia, intencionado pedagogicamente. Porém, sem desprezar possíveis efeitos do uso das tecnologias e jogos digitais oriundos dos ambientes sociais e, porventura, adicionados aos ambientes da educação formal.

\section{Resultados e análises da oficina do jogo digital como possibilidade de ferramenta pedagógica}

O percurso metodológico empregado neste estudo alinhou-se aos pressupostos da abordagem qualitativa, de natureza exploratória e teve como objetivo levantar as impressões dos participantes quanto aos aspectos da oficina "jogo digital como ferramenta pedagógica", por intermédio de aplicação de questionário.

A concretização da oficina possibilitou a experimentação do jogo digital como ferramenta pedagógica por meio de atividades mediadas pelo dispositivo Kinect Xbox One para simular a prática corporal nas modalidades de dança, jogos, esportes e lutas. As 
atividades propostas foram planejadas em três momentos e dinamizadas por três professores nas seguintes etapas: (1) experimentação dos jogos digitais; (2) fundamentação teórica e (3) prática em pequenos grupos.

As atividades foram iniciadas com uma breve explanação dos objetivos e apresentação da dinâmica de desenvolvimento, o primeiro momento, com cerca de uma hora, possibilitou a experimentação dos jogos de movimento kinect pelos participantes, bem como favoreceu o momento inicial de interação entre os participantes. Posteriormente, por meio de palestra online, os participantes tiveram a oportunidade de conhecer os conceitos teóricos, desafios e aspectos didático-pedagógicos dos jogos digitais. $\mathrm{Na}$ sequência (momento de prática) os participantes foram convidados a formar duplas e trios e receberam o desafio de pensar uma estratégia didática de aplicação dos jogos vivenciados na fase de experimentação. Na fase de aplicação, todas as duplas tiveram a oportunidade de dinamizar a prática pedagógica pensada para todo grupo.

$\mathrm{Na}$ finalização do evento foi proposta uma Roda de Conversa para discussão dos aspectos didático-pedagógicos dos jogos digitais e seus desafios como ferramenta pedagógica. Por fim, os participantes responderam o questionário de avaliação de reação, dados sistematizados abaixo com breve perfil dos participantes e suas impressões quanto aos aspectos de Organização, Dinamização, Conteúdo apresentado, Duração das atividades, Interação, Apoio técnico, Local (sala), Apoio da equipe de facilitação, Gamificação das atividades, Expectativa com a oficina, conforme apresentado no quadro 1 :

Quadro 1- impressões dos participantes quanto aos aspectos da oficina jogo digital como ferramenta pedagógica

\begin{tabular}{|c|c|c|c|c|c|}
\hline Categorias & \multicolumn{5}{|c|}{ Escala Likert } \\
\hline Perguntas & 1 & 2 & 3 & 4 & 5 \\
\hline Organização & - & - & - & 7 & 11 \\
\hline Dinamização & - & - & 1 & 1 & 16 \\
\hline Conteúdo apresentado & - & - & - & 3 & 15 \\
\hline Duração das atividades & - & - & - & 5 & 13 \\
\hline Interação & - & - & 1 & 3 & 14 \\
\hline Apoio técnico & - & - & - & 7 & 11 \\
\hline Local (sala) & - & - & - & 2 & 16 \\
\hline Apoio da equipe de facilitação & - & - & - & 3 & 15 \\
\hline Gamificação das atividades & - & - & 1 & 2 & 15 \\
\hline Expectativa com a oficina & - & - & - & 4 & 14 \\
\hline Motivação para o aprendizado & - & - & - & 4 & 14 \\
\hline Contribuições para aprendizagem & - & & - & 1 & 17 \\
\hline
\end{tabular}

Fonte: Elaborado pelos autores (2018)|

Sinteticamente, buscou-se levantar as impressões dos participantes quanto aos 
aspectos da "Oficina Jogo Digital como ferramenta pedagógica", considerando a escala likert de satisfação - (1) Muito Fraco, (2) Fraco, (3) Razoável, (4) Bom e (5) Muito Bom.

Os dados acima demonstram que o critério "(5) Muito Bom" se apresentou com grau significativo de satisfação quanto à participação na oficina. Observa-se que as doze categorias elencados obtiveram pontuações máximas. Não obstante, o critério “(4) Bom" também expressou de forma acertada e adequada o alcance dos objetivos na visão dos participantes. Ambos os critérios, são complementares e confirmam os relatos verbalizados na "roda de conversa" que o evento, de modo geral, foi significativo e produtivo.

Quanto à motivação para o aprendizado, Contribuições para aprendizagem, sendo alguns desses elementos constituintes da organização do trabalho pedagógico para aplicação de tecnologias em sala de aula.

Referente ao perfil dos participantes o evento contou com a presença de 18 pessoas interessadas na temática, desses 11 declaram-se do sexo feminino e 7do sexo masculino. Na faixa etária observou-se 5 participantes com menos de 21 anos; 10 entre 21 e 30 anos; 1 participante entre 31 e 40 anos, e 1 entre 51 e 60 anos. Quanto a habilitação acadêmica destacou-se 16 participantes de Licenciatura e 2 de Bacharelado, sendo apenas um desses participantes com titulação de Mestrado. Referente à área de formação participaram, 8 estudantes do curso de Pedagogia, 4 da licenciatura em Educação Física, outros 5 participantes não declararam a área de formação.

Além do breve perfil, questionou-se ao participante se "Foi a primeira vez que participou de Oficina com aplicação de tecnologia para fins pedagógicos? " À vista do questionamento, 12 participantes confirmaram ser a primeira participação e, outros 6 confirmaram terem vivenciado alguma formação de tecnologia aplicada a educação. Também foram questionados acerca do envolvimento do participante em atividades semelhantes feitas anteriormente, assim questionou-se "Qual foi o seu desempenho na última oficina que frequentou" os resultados demonstraram que 13 pessoas participaram integralmente e 5 participaram parcialmente da última oficina que frequentaram.

\section{Considerações Finais}

A oficina "Jogos Digitais como possibilidade pedagógica na prática corporal", realizada no contexto da Semana Universitária da UnB, teve como proposta pensar a prática pedagógica nas aulas de educação física alinhada ao conceito de (ciber) cultura corporal 
do movimento mediado por jogos digitais. O evento realizado no âmbito da Faculdade de Educação Física também buscou integrar estudantes de graduação na área de Educação Física e Pedagogia, assim como professores da rede pública/privada de ensino e pessoas interessadas na temática.

Observou-se durante a aplicação da oficina jogo digital como possibilidade de ferramenta pedagógica, objeto deste relato, que as repetições dos movimentos dos participantes possibilitaram, para sua grande maioria, mudanças de comportamentos à medida que exercitavam com os jogos digitais, de forma direta ou espelhada das reproduções dos movimentos de seus colegas que estavam à frente, ao lado ou na própria tela do monitor da atividade corporal.

Neste relato de experiência ficou demonstrado que os jogos digitais e suas ramificações lúdicas devem ser aplicados em ambiente educacional com intencionalidade pedagógica, entre outras premissas, concebida por ações democraticamente pensada, discutida e (re) planejada junto com a comunidade escolar, para ser executada em sala de aula ou ambiente educativo pelos atores diretamente envolvidos naquela prática educacional.

\section{Referências}

FRANCISCO, D; SILVA, A.. Criança e Apropriação Tecnológica: um estudo de caso mediado pelp uso do computador e do tablet. HOLOS, 2015, Vol.31(6), pp.277-296.

BARACHO, A.F.O.; GRIPP, F.J.; LIMA, M.R. 2012. Os exergames e a educação física escolar na cultura digital. Revista Brasileira de Ciências do Esporte, 34(1), 1-10.

CARVALHO, L. A. C.; BARBOSA, M. W.; SILVA, V. B.. Proposta e avaliação de uma abordagem lúdica para o ensino de histórias de usuário e scrum. Revista de Gestão e Projetos, 2014, Vol.5(3), p.44(15).

CRUZ JUNIOR, G. Entre bolas, cones e consoles: desafios dos jogos digitais no contexto da Mídia-Educação (Física). Revista Atos de Pesquisa em Educação, Blumenau, v. 8, n. 1, p. 287-305, 2013. Disponível em: . Acesso em: 04 maio 2018.

COSTA, P.; FERNANDES, G. Ensinando crianças do ensino fundamental a programar computadores com o auxílio de jogos digitais. Revista Tecnologias na Educação - Ano 8 - Número/Vol.16 - Edição Temática - Congresso Regional sobre Tecnologias na Educação - Setembro 2016 - Acesso em: 04 maio. 2018. Disponível em: 
tecnologiasnaeducacao.pro.br

FRASCA, G. Videogames of the opressed: videogames as a mean for critical thinking and debate. Georgia: Georgia Institute of Technology, Mastery Thesis, 2001.

HUIZINGA, J. Homo Ludens. São Paulo: Perspectiva, 2008.

JUUL, J. A casual revolution: reinventing video games and their players. Londres: The MIT Press, 2010.

RAMOS, D.K.; SEGUNDO, F. R. Jogos Digitais na Escola: aprimorando a atenção e a flexibilidade cognitiva. Educação \& Realidade, Porto Alegre, v. 43, n. 2, p. 531-550, abr./jun. 2018.

THE ECONOMIST. The most successful video-games consoles. Disponível em: . Acesso em: 28 abril 2018.

NASCIMENTO, L. C. R; LIZ, A. P. C. Jogos Digitais no Ensino da Língua Portuguesa para Crianças Surdas. Periferia (Duque De Caxias), v. 9, p. 263-289, 2017. 